\title{
Designing for Empathy in a Church Community
}

\author{
Jonny Huck \\ Paul Coulton \\ Adrian Gradinar \\ Imagination Lancaster, \\ Lancaster University \\ \{j.huck2; p.coulton; a.gradinar \} \\ @lancaster.ac.uk
}

\author{
Phillip Powell \\ Jennifer Roberts \\ InstEAD, \\ University of Sheffield \\ \{j.r.roberts; p.a.powell $\}$ \\ @sheffield.ac.uk
}

\author{
Andrew Hudson-Smith \\ Martin De-Jode \\ Panagiotis Mavros \\ CASA, UCL \\ $\{$ a.hudson-smith; \\ m.dejode; p.mavros \} \\ @ucl.ac.uk
}

\begin{abstract}
Whilst empathy is considered an essential component of what makes us human, it is arguably absent as a specific design element when creating modern communications. As such, this paper presents an approach to designing for empathy. We consider how design interventions related to a personal ritual within a church community may be extended and augmented in order to allow the concerns of individuals to be shared more widely between community members. It is intended that these interventions will promote conversation and support within the community, thus generating empathy.
\end{abstract}

\section{Categories and Subject Descriptors}

H.5.m Miscellaneous

\section{General Terms}

Design, Human Factors

\section{Keywords}

Empathy; Design; Digital Empathy; Internet of Things

\section{INTRODUCTION}

\subsection{Empathy}

Empathy, the ability to understand and share the feelings of another [1]; is an emotional capacity that has arguably been overlooked in the design of digital systems [2]. Empathy may, however, be viewed as one of the essential components of the 'human condition', with observation of atypical empathetic responses suggested as indicators of a number of autism spectrum and personality disorders that inhibit an individual's ability to relate to others. If empathy is indeed such an important facet of communication between humans, we argue that it should be considered in the design of all communication systems. Given this, and in the absence of a full understanding of how designers might address this goal, there is a clear need for research that specifically addresses the notion of designing for empathy [2].
There is a rich and varied literature relating to empathy, how it is experienced, whether and how it may be taught, its effect upon attitudes and behaviour, and its application to a wide variety of applied fields of study [3]. Nevertheless, empathy has yet to be completely understood. It is probable that the lack of progress relating to the incorporation of empathy within digital design is caused by the notion that it, along with other emotions, is considered to be extremely difficult [3], or even impossible [5, 6] to sense automatically with a computer. The approach taken here, however, is not to attempt to sense empathy, but merely to design systems in such a way as to afford empathetic feelings and behavior within a community for the purpose of increasing wellbeing.

It is worthy of note that the concept of designing for empathy is completely distinguished from the similarly named field of 'Empathic Design', which is concerned with approaches whereby the designer develops empathy for the users. There is, in fact, very little in the current design literature relating to the creation of systems for facilitating or encouraging empathetic behaviour between subjects [2].

\section{METHODOLOGY}

\subsection{Designing for Empathy}

This work has taken place in collaboration with an existing community: the congregation of St Peter De Beauvoir Town Anglican Church in Hackney, London. A church community was chosen as they already have a number of rituals in place for members to share their prayers and worries in a personal way with God, and it is one of these rituals that will be augmented in order to enable the associated thoughts and feelings to be shared with their community. It is intended that this will afford the development of empathy. This work builds upon the existing work relating to other rituals in the same church [2].

There is a significant strand of the psychological literature that attests to the potency of physical acts and 'rituals', demonstrating the notable and sometimes surprising effects that behaviour can have on the human psyche. The link between mind and body has been explored most profitably in an area that has become known popularly as 'embodiment' or 'embodied cognition'; the concept that certain states of the body modify states of the mind; [8]. This project aims to build upon this, and lever the effect of embodied cognition in order to develop understanding and empathy within the community.

The system to be explored with the aim of supporting empathy is that of the font, which is used at St Peter De Beauvoir Town 
church as a means for members of the congregation (normally children) to 'let go' of their fears and worries, by the symbolic embodied action of placing a pebble (representing the worry) into the water and physically letting go of it. Whilst not the traditional function of the (baptismal) font in a church ${ }^{1}$, this ritual represents an effective example of embodied cognition, and as such can benefit the individual involved. In the current system, these worries are currently kept privately to the individual and not shared either with the vicar or other members of the community.

The objective of the digital font is to increase engagement with the ritual and facilitate communication within the community relating to their collective worries in order to further develop understanding and empathy between community members. The current font ritual already represents a very effective literal representation of 'letting go' of one's worries, and as such it was seen as vital to maintain this in the design of the augmented version. For this reason, the approach taken here will be a noninvasive digital augmentation of the existing font within the church, which will provide a novel visualisation in order to promote engagement, as well as the functionality required for the communication of worries to the rest of the community.

\subsection{Digital Font}

The "Font of Solace" digital font comprises the existing stone font that is housed within the church (Figure 1), a Samsung Galaxy Note Tablet with S-Pen stylus and the Android operating system, a Microsoft Kinect, a projector, and a computer with the Windows operating system and running the 'ubidisplays' software application [10].

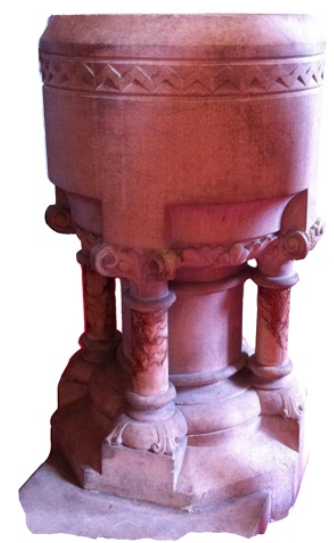

Figure 1. The Stone Font at St Peter De Beauvoir Town Church, Hackney, London, UK.

The tablet is running a custom application that allows the user to 'write' their worry onto the screen using the provided stylus, before pressing a button in order to 'send' this worry to the font. The rest of the equipment acts to make the font interactive, with the projector displaying the message from the tablet onto the surface of the water in the font, the Kinect detecting user

\footnotetext{
${ }^{1}$ A baptismal font is normally used as part of the Christian sacrament of Baptism (also known as Christening by some Christian denominations), whereby holy water from the font is symbolically poured over the head of the subject (normally a child), as part of their initiation into the church.
}

interaction with the water in the font, and the computer running the 'ubidisplays' software tying the two together. A reflective plastic disk is placed in the water, which optimizes the appearance of the image from the projector.

This setup allows the user to 'place' their message into the font by physically putting their hand onto the surface of the water (as they would to place a pebble into it), and then watch the words that they wrote slowly appear in the water before sinking and drifting away into the virtual 'ether'. In order to make the image of the writing appear clearer in the water, it first undergoes some image processing; inverting the colours and thickening the writing to make it stand out better. This process is illustrated in Figure 2.

This hand-written message is logged (as an image) to a central server, and requires approval from the vicar before appearing on a public display within the church, in order to prevent abuse. This display will cycle through all of the most recent worries that people have logged, so that they may be shared with the rest of the community, for the purpose of generating empathy. The vicar will also use the system to maintain her own list of prayers for members of her congregation, which can become easily outdated in the current, non-digital system.

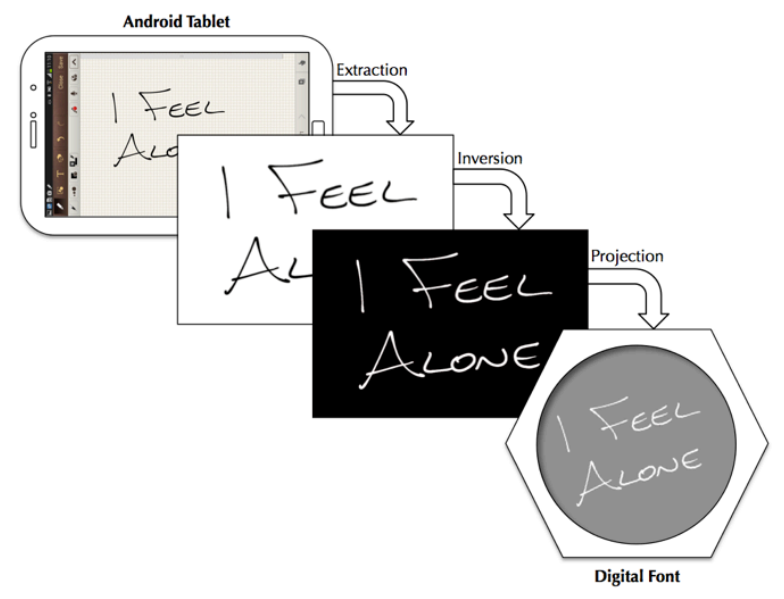

Figure 2. Illustration of the extraction, inversion and projection of a worry onto the water in the Digital Font.

The decision to design a system around the existing font in the church, as opposed to the construction of a new artefact was taken for reasons of both aesthetics and usability. The addition of computing equipment that does not require to be physically attached to the font itself means that the appearance of the font is not affected whatsoever, and as such it may still be used unimpeded for its primary purpose of a baptismal font, and even for dropping pebbles in for those not wishing to use the augmented system. As the font is already familiar to the users, it is hoped that people will feel more comfortable engaging with it, and so will be more likely to use the system. Furthermore, it could be considered that, in many ways, there could be no better way to achieve a familiar 'church aesthetic' than to utilise the extant furniture of the church itself.

The use of hand-written text is intended to make the input seem more 'natural' and less 'modern', with the action of writing perhaps appearing to be less onerous a task for the user, and 
affording them a greater sense of freedom of expression in the description of a worry than would typing. A user would even be free to augment their worry with a drawing if they wished. Furthermore, a user seeing the disappearing worry represented in their own handwriting may help to make this ritual appear more personal than it would in an anonymous typeface, increasing the 'embodiment' of the action.

Triggering the process by the user physically touching the water has been used as a powerful symbolic embodied action, which it is hoped will prove much more effective as a physical metaphor for "letting go" of a worry, when compared to simply pressing a button, or interacting with a screen. It is therefore intended that the use of this physical action will generate benefits to the user through embodied cognition, allowing them to feel as though they had figuratively 'let go' of their worry.

It is hoped that this augmentation to the existing system will increase the effectiveness of the font as a symbol of 'letting go', with the addition of a novel and engaging visualisation of the worries "disappearing" into the font in lieu of the pebbles. Worries that are logged in this way will be shared within the community and, as with the prayers shared through the digital votive candles, it is hoped that this will promote communication and afford empathy on these normally private topics.

\section{CONCLUSION}

Whilst very much a 'work in progress' this work is intended to stimulate debate around designing for empathy. A system has been presented that allows a congregation to communicate their worries not only to God, as is currently the case, but also to the vicar and other members of the community through existing ritual acts. It is intended that these rituals will have a positive effect upon the psyche of users through embodied cognition; and that this communication will enable the community to be more aware of its own members, develop a greater understanding of each other, and afford the development of mutual empathy.

Our approach centred upon the use of an existing cohesive community, and upon the principle of extending the functionality of existing symbolic rituals and their associated artefacts within the church setting. This approach has minimised the required level of motivation for community members to use these the proposed system, as it is based upon a ritual that they are already familiar with. Similarly, the selection of a pre-existing community is intended to facilitate conversation, as community members would be expected to feel more able to talk to each other than may be the case with a group of strangers.
Future work on this project will comprise an evaluation of the effect of this systems, along with that described in [2], in the church, and the extent to which they were able to afford the development of empathy within the community.

\section{ACKNOWLEDGMENTS}

The authors would like to thank Julia Porter-Pryce, Vicar of St Peter De Beauvoir Town, for her support and enthusiasm for this project and the EPSRC through grant EP/L003635/1.

\section{REFERENCES}

[1] Oxford Dictionaries: http://www.oxforddictionaries.com/definition/english/empath y. Last accessed 04/08/2014.

[2] Coulton, P., Huck, J., Hudson-Smith, A., Ralph, B., Mavros, P., Roberts, J., \& Powell, P. (2014). Designing interactive systems to encourage empathy between users. In DIS Companion '14 Proceedings of the 2014 companion publication on Designing interactive systems. (pp. 13-16). New York: ACM. 10.1145/2598784.2602770

[3] Belman, J., \& Flanagan, M. (2009). Designing Games to Foster Empathy. International Journal of Cognitive Technology, 14(2), 11.

[4] Ekman, P. (2003). Emotions Revealed: Recognizing faces and feelings to improve communication and emotional life. New York: Times Books.

[5] Gaver, W. (2009). Designing for emotion (among other things). Philosophical Transactions of the Royal Society B: Biological Sciences, 364(1535), 3597-3604.

[6] Boehner, K., DePaula, R., Dourish, P., \& Sengers, P. (2005, August). Affect: from information to interaction. In Proceedings of the 4th decennial conference on Critical computing: between sense and sensibility (pp. 59-68). ACM.

[7] Wilson, A. D., \& Golonka, S. (2011). Embodied cognition is not what you think it is. Front Psychol, 4: 58

[8] Zhong, C-B., \& Liljenquist, K. (2006). Washing away your sins: Threatened morality and physical cleansing. Science, 313, 1451-1452.

[9] Hardy, J., Ellis, C., Alexander, J., \& Davies, N. (2013, June). Ubi Displays: A Toolkit for the Rapid Creation of Interactive Projected Displays. In The International Symposium on Pervasive Displays 